\title{
Sciendo
}

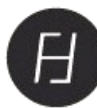

Studia Humana

Volume 8:2 (2019), pp. 47-54

DOI: $10.2478 /$ sh-2019-0017

studia humana

QUARTERLY JOURNAL

\section{Moral Considerability and Decision-Making}

\author{
Magdalena Hoły-Łuczaj \\ University of Information Technology \\ and Management in Rzeszow, \\ Sucharskiego 2 Street, \\ 35-225 Rzeszow, Poland \\ e-mail:mholy@wsiz.rzeszow.pl
}

\begin{abstract}
:
The paper revisits metaphysical and deontological stances on moral considerability and offers a new criterion for it - "affectability", that is a capacity of an agent to affect a considered entity. Such an approach results in significant changes in the scope of moral considerability and is relevant for discussing the human position in the Anthropocene. This concept, given especially the assumption of the directness of moral considerability, is also substantial for the decision making process on the ethical, as well as the political plane.

Keywords: moral considerability, non-human beings, decision making, science advice.
\end{abstract}

\section{Introduction}

The paper aims to contribute to the discussion on moral considerability by offering a new criterion for it, which can redefine its scope. The issue of moral considerability is related to the question to whom our actions should be morally considered. It was not asked for ages since ethics took as obvious that only relations with people (whose definition has changed over the centuries) need to be evaluated this way.

The first to oppose this claim was environmental ethics. It holds that our dealings with nonhuman natural beings should be morally assessed, or, to put it differently, non-human natural beings deserve to be considered morally and to be treated correspondingly. This state of 'deserving' is referred to as 'moral considerability' [1].

The set of non-human (natural) beings is, however, internally very diverse and thus the question which specifically should be within the scope of moral considerability and on what criterion is the core issue in the debate on that matter. Most commonly employed approach in defining it was a "metaphysical" one - oriented toward indicating a trait of a considered being which can qualify it to have moral considerability. It is opposed by a "deontological" stance, according to which we should think of moral considerability in terms of obligations of an agent (the one who performs the action) [2]. In the paper, I critically compare and revisit both stances. I shall 
argue, building upon this reexamination, that a valid criterion for granting moral considerability for an entity should be a capacity of an agent to affect it.

My argument will be structured as follows. First, I introduce the idea of moral considerability. Next, I reconstruct the debate on criteria of moral considerability and groups of being granted it accordingly. In the third section, I revisit deontological approach to moral considerability. In the final part, I lay out the concept of affectability as the criterion for moral considerability.

\section{Moral Considerability}

The term "moral considerability" was coined by Kenneth Goodpaster in 1978 [1]. It defines the status of a being which requires human beings to consider implications of their actions toward this being in normative terms.

This idea is complementary to the concept of 'moral patienthood' as distinct from 'moral agency.' The class of moral patients is the class of beings to whom we consider that we owe ethical obligations, whereas moral agents are defined as that class of moral patients, usually only human beings, to whom we owe obligations and who, in turn, are held to be morally responsible for their actions. This distinction assumes that all moral agents are moral patients, but not all moral patients are moral agents [3]. By the same token, beings which can be granted moral considerability do not need to morally consider their actions.

The tendency to shift the boundaries of moral considerability toward non-human beings is closely linked to the efforts to uproot anthropocentrism and related to it the perspective of subordination of one being to another. It is believed that only such a move will enable us to eradicate mechanisms of violence and control [4]. Yet, today there is also another approach, which argues that only when we admit that not only human beings are agents, human hubris will be restrained. The belief that solely human beings are agents is often thought to result in that there are no constraints to their activity which becomes destructive hyperactivity. This can be observed in our current situation to which we refer as to the Anthropocene.

This name was suggested by the Nobel prize-winning atmospheric chemist and climate scientist Paul Crutzen [5], [6]. He believed that this is the most apt expression to describe current instable and unpredictable state of the Earth [7]. Even though neither the International Commission on Stratigraphy nor the International Union of Geological Sciences has yet officially approved the term as an indication of a particular geological period, the idea of the Anthropocene became a great source of inspiration for scholars working in various fields, creating new frames for their investigations.

The concept of Anthropocene consists basically of two assumptions. First, that the human (anthropos) has gained geological agency and has become the most important geological factor on the planet, trumping all the natural (non-human) factors. That is to say, the anthropos becomes a geological layer, just like ice before, in the sense that human agency determines the face of the Earth. Second, that it severely changed the Earth's atmosphere and biosphere, resulting in global warming and the collapse of vital ecosystems [7], [8].

In this sense, the Anthropocene is the epoch of fulfilling anthropocentrism and all its threats. The remedy for that, according to some scholars, is granting agency - including its moral dimension - also to non-human beings. The representatives of such an approach are primarily posthumanists. They put a premium on the activity of non-human beings, arguing that taking away agency from non-human beings supported a human sense of superiority, which translated into an arrogant way of dealings with beings other than human [9]. To eliminate this practice, posthumanists emphasize the ability of things to act, which according to them is the most solid ground for ascribing things a moral status.

Decreasing human hubris by means of ascribing moral agency to non-humans can have however one unintended result: decreasing human responsibility. If human beings could say that this is not only their wrongdoing to Earth but also, for instance, of some machines, it would wash 
away human guilt. And this is undesirable. Thus, I argue we should rather get focus on the problem of moral considerability to make human beings realize that they have to think, in ethical terms, not only about their fellow humans, but also about many other beings in the world. The question remains which non-human beings this should concern.

\section{Metaphysical Criteria of Moral Considerability}

The debate about criteria of moral considerability is inseparable from the discussion on beings that should be granted it. In what follows, I briefly reconstruct the main positions in this discussion.

Before the crystalizing the idea of moral considerability, Aldo Leopold, the founder of environmental ethics, claimed that we should morally respect nature as a whole for how harmoniously it functions, among other reasons [10]. Following such a claim, "a thing is right when it tends to preserve the integrity, stability, and beauty of the biotic community. It is wrong when it tends otherwise" [10, p. 15]. By this token, the feature which qualifies some being to moral considerability is the ability to affect ecosystems (this approach was thus referred to as "land ethic").

With this perspective, however, we can lose sight of the good of individual beings, such as animals from non-endangered species [11]. Thus, environmental ethicists started to advocate ascribing moral considerability to particular groups of non-human beings. Peter Singer argued that such a capacity should be granted only to animals, as they are sentient beings that are able to suffer/feel pain [11]. So if the spectrum comprises only human and non-human animals, improper behavior would be inflicting pain, while proper behavior would entail helping it to avoid, reduce or cure its pain/suffering.

Other theorists found that rationality, the capacity to suffer and to enjoy, or having interests are all arbitrary stopping points and thus they argue the above limitation is too restricted and we need to include also animate beings (e.g., plants) into the domain of ethics as living beings teleological centers of life [12], [1]. Granting moral considerability to all animate beings results in that its criterion is whether we hinder or enable the self-development/self-reliance of such being.

Another group of environmental philosophers took a step further and argued for the moral considerability of inanimate natural beings (rocks, mountains, rivers) insofar as they belong to the sphere of physis, or natural order [13], [14]. If we take into account inanimate beings as well, the criterion of moral considerability is whether we interfere or help maintain their existence and integral identity. Of course, the above criteria apply upwards. For instance, the criterion of avoiding pain concerns exclusively sentient animals, but the right to be undisturbed is valid for all beings.

Extending the limits of moral considerability shows also how important is the directness of moral consideration and responsibility is [15], [16]. Only direct attention, being focused on the particular type of things, guarantees sufficient respect for them, eliminating the threat that their well-being will be overlooked or ignored for the sake of some other, more human-like being or nature as a whole.

The last caveat is not accidental: the horizon of moral considerability for environmental ethics is nature (either as whole or as the set(s) of individual natural entities). What about other beings? For instance, artifacts? They seem to be excluded by default. A good illustration of this problem is Thomas Birch's theory of a "universal consideration."

Thomas Birch was very sympathetic to the idea of widening the scope of moral considerability to non-human beings discussed in the sphere of environmental ethics. Birch accused, however, environmental ethicists of marasmus - getting bogged down in pointing to a specific feature of beings which should be a final criterion for granting them moral considerability. He challenged this need, offering a remedy which would be a 'universal consideration'. Its basic principle is simply taking everything into moral consideration in a given situation [16, pp. 314, 331]. He defined "to consider X morally" as attending, looking at, thinking about, sympathizing with $\mathrm{X}$, etc. with the goal of discovering what, if any, direct ethical obligations one has to X [16, $\mathrm{p}$. $315]$. 
Such an approach seems to be very promising and open new possibilities for ethics concerned with non-humans, significantly broadening its scope. Unfortunately, it is only seemingly so. Even though Birch writes about "everything" [16, pp. 313, 314, 318, 321, 327, 330.] or "all others of all sorts" [16, p. 313] throughout the entire text, at the end he makes clear that "all things" refer solely to the "whole biosphere" [16, p. 331]. He does so without further explanation. We can only suspect that this is due to perceiving artifacts as inferior in environmental ethics as they lack intrinsic worth understood as a non-instrumental value. We can challenge such a framing of the problem of intrinsic worth can by pointing to the functionality of nature and mutual dependency of all the natural beings, but analyzing this problem goes beyond the scope of the paper. What is important for us is that Birch's position turns out to be also grounded in metaphysical claims, even though some scholars read his theory as a deontological one, on which we comment in the next section.

But before we discuss that let us note there are approaches which advocate taking artifacts into moral consideration. An example of that can be Luciano Floridi's "information ethics." Information ethics suggests that there is something even more elemental than life, namely being that is, the existence and flourishing of all entities and their global environment - and something more fundamental than suffering, namely entropy. Entropy here refers to any kind of destruction or corruption of informational objects, that is, any form of the impoverishment of being including nothingness, to phrase it more metaphysically [17, p. 47], [18, p. 146]. According to this, "what makes someone or something a moral patient, deserving of some level of ethical consideration (no matter how minimal), is that it exists as a coherent body of information. Consequently, something can be said to be good, from an IE perspective, insofar as it respects and facilitates the informational welfare of a being and bad insofar as it causes diminishment, leading to an increase in information entropy" [17, p. 300], [18, p. 146].

The question is whether everything which has a body of information can be in fact destroyed, or, if we would like to nuance this objection, we can ask whether beings vary when it comes to their permanent damaging and destroying. Digital beings seem to be in a significantly different situation in this regard than physical ones. Likewise, it appears that ideal beings cannot be destroyed or altered to any extent. These remarks, however, are not to challenge Floridi's stance, but to show that his sound and inspiring theory calls for further examination. In this paper, however, I suggest approaching the problem of moral considerability from yet another angle. Namely, $a$ capacity of an agent to affect a particular being.

However, before elaborating on this, we shall investigate insightful criticism of the above metaphysical concepts of moral considerability offered by deontological stance.

\section{Deontological Criticism}

Aforementioned Thomas Birch's theory of universal consideration received significant feedback [19], [20]. Among scholars who responded to that concept, more or less critically, was Benjamin Hale. He offered, being inspired by Birch's stance, a "deontological approach" to moral considerability.

The core claim of it is that "moral considerability should be understood narrowly and centrally as an agent-relative deontological question" [2, p. 37]. Hale argues that moral considerability is better understood as a question about a moral agent's duty than about a moral patient's status. Hale holds that rather than focusing on the properties, attributes, or capacities of other beings that qualify them as moral patients, we instead should focus on the obligations of rational agents to consider others [2, p. 37].

Hale explains his position in the following way: if we ask whether something is comprehensible, for instance, it would be odd to say that it "has" comprehensibility. We ask ourselves the question "can we comprehend it?" and do not seek to locate this comprehensibility in any of its constituent parts. Thus, when we suggest that something is comprehensible, we ask about its comprehensibility, and we suggest that it is or is not comprehensible for us [2, p. 41]. This allows Hale to conclude that moral consideration is an obligation of the agent [2, p. 45]. 
According to him, such a perspective offers a fresh solution to a problem that has plagued environmental ethicists for years. Hale, following Birch's criticism, says that seeking to establish a ground for moral considerability in a specific attribute of a particular group of beings leads to a dead-end - environmental ethicists cannot reach the consensus which beings deserve moral consideration.

Hale's stance is, however, entangled in a metaphysical presupposition about the superiority of nature in a similar manner as Birch's is. We can see it if we take a look at the assumption of considering everything. While Hale believes we must consider all about implications of our behavior, he does not think that all entities in the world are morally considerable [2, p. 39]. That is to say, he suggests that "everything must be considered - all factors unique to a given situation must be considered - not that every object or entity in the world is morally considerable" [2, p. 40]. Entities which he excludes are artifacts. Unlike Birch, he does so explicitly and comments on that, referring to the fact that the production of artifacts requires the use of natural resources. He says that it would be "double counting" [2, p. 50]. Hale argues that creators have already considered their component parts when producing specific artifacts. In his view, only damaging a tree (by cutting it) to produce a chair deserves moral consideration, while damaging a wooden chair does not as it is made from an already cut tree [2, p. 50]. So for Hale only other humans, animals, plants, or mountains are worthy of our moral attention [2, pp. 40, 47].

I do not agree with such a justification, but I believe Hale's criticism is worth attention. In what follows I offer, drawing upon ideas from a traditional metaphysical stance on moral considerability, as well as a deontological approach to it, a new criterion: affectability.

\section{Affectability}

What is particularly interesting in the theory of universal consideration, as well as deontological stance to moral considerability is the emphasis on human responsibility. They make us aware this is our doing which we need to think about. We cannot forget that these are our actions that we assess in the act of moral consideration. Shifting the burden of proof on human beings in developing the idea of moral considerability does not have anthropocentric connotations here. It rather reminds us that non-human beings can be harmed or benefited by human beings. This is an undeniably significant advantage of Birch's and Hales positions.

Furthermore, Birch's theory nicely explains the nature of consideration in moral consideration. It shows it is a specific attitude, or a willingness to be reflective about one's own behavior, rather than making calculations concerning each separate action, which would be quite alien to our everyday practices. Unfortunately, this is the direction in which Hale's concept is heading. He argues that "we are obligated to consider as much as is practically feasible" [2, p. 45] and that "whatever the case, to reframe the question of moral considerability deontologically only demands that we are obligated to consider the full spectrum of features of our actions before we act" [2, p. 50]. Such deliberations, however, seem to be quite unrealistic. My skepticism about it should not be read as a call for being thoughtless. On the contrary, I believe moral considerations are a significant component of making decisions process, but in the way Birch proposes it, not Hale.

Another drawback, this time of both stances, is that they do not explicate hidden metaphysical assumptions, of which they were supposed to be free of. To paraphrase Hale, their approaches mask the metaphysical underpinnings of the question [2, p. 41]. First, these theories are limited to natural beings. Birch does not explicate why, but we can assume he think they are of inferior status, while Hale directly states that he believes artifacts are secondary to natural entities (as produced from them). He sees his position as related to consideration level, but in fact he holds strong metaphysical assumption on that artifacts are not fully-fledged beings.

But this "metaphysical" objection can go further. Birch and Hale speak of considering "everything" or "every being": what if we were to take the terms literally? Between the biosphere, to which both theories in question are limited, and "everything" stretches the ontological abyss, which is inhabited not only by artifacts but also by, depending on ontology one accepts, fictional 
beings, abstract object, universals, tropes, properties, etc. Should they be morally considered as well, along with, for instance, concrete individuals? We need to review the answer in terms of what morality and ethics are about.

The most straightforward description is that morality and ethics deal with actions, or more precisely, actions affecting other beings [21, p. 20]. Ethics is then the analysis of the specific relationship between two subjects (an agent and its patient) - how one affects the other, changes it, makes a difference to it, etc.

In accordance with this claim, only those beings that we are able alter or impact can qualify in the domain of ethics. By the same token, ethics cannot include beings that human beings (or any other beings) cannot affect. This is the case for abstract beings (if we accept their existence), such as the color white, the idea of a triangle, acidity, or fictional beings, such as literary characters [22, pp. 19-20]. The (ideal) triangle is by definition immune to any changes. We cannot make it better or worse, thus we cannot consider it morally - we can think about (consider) it, but only in a nonmoral way.

The entry-level in moral considerations should be then not the measure of ontological "perfectness," but the possibility to affect something. It is not that abstract or fictional beings do not deserve to be considered morally; we are simply unable to relate with them in this way. That is to say, moral considerability is not about the respect and reverence for such beings, but only about the possibility to influence them.

We need to consider then the implications of our actions toward other entities. To what extent do we influence them, how permanent are changes introduced by us, if these effects are irreversible or not, etc. When thinking about the appropriate course of action, we should take into account what actually can be harmed, damaged, violated, trespassed upon, and so on. In this sense, the capacity to absorb moral consideration is grounded in both a trait of an entity in question and agent's ability to impact this entity.

These questions become of crucial significance when considering our activity towards those with whom we are asymmetrically related [see 2, p. 57]. In such a case, it often turns out that entities which were "mere things" start to matter morally. A good illustration of it can be the aforementioned artifacts. When we directly devote our attention to them, they become able to reveal their unique character as concrete individuals. This may support our willingness to care for them and not replace them so easily in a more effective way than threatening us with harming nature by making more waste (when we dispose our things) and using more natural resources (to produce a new artifact).

The above example also illustrates how the issue of moral considerability is substantial in decision-making. It concerns both the ethical plane, as well as the political. Moral considerability does not only shape our moral sensitivity as individuals, but is also an important factor in setting pro-environmental policies. For instance, including artifacts to the scope of moral considerability can translate into alternative strategies of reducing plastic waste. Instead of negative argumentation (plastic things as a threat to nature - garbage, use of resources, etc.), we can provide a positive one by appealing to that they are our belongings for which we are responsible.

Finally, referring to the idea of moral considerability in policy- and decision-making can be read as the case of science advice. Thanks to using philosophical arguments, we can challenge existing patterns of actions and construct new ones, or we can validate and strengthen ideas from outside of the mainstream to build better society and better future for the planet [23, p. 238].

\section{Conclusions}

The debate on moral considerability encourages us to widen its scope. We invite to this club, to cite Thomas Birch, more and more non-human beings, agreeing we cannot cut them out of the picture when thinking of the sphere of ethics [16]. The question remains, however, how inclusive this club can be. Difficulties in finding a trait of the entities which should be granted moral considerability prompted some scholars to claim that simply everything deserves such our attention. This 
assumption was accompanied by the claim that we should place the burden of proof on the agent ("deontological" stance), and not on the patient ("metaphysical" stance), when addressing the problem of moral considerability. This paper offers a third way. It argues that the criterion should be affectability: a possibility of an entity to be affected by an agent, or, looking form the other side, an ability of an agent to affect in any way a given entity. In doing so, such an approach attempts to achieve equilibrium between "deontological" and "metaphysical" stances by showing that moral considerability of a particular entity should be grounded in the ontological condition of it as well as agent's ability to affect it. This deontological aspect of moral considerability, which translates into highlighting human responsibility for the actions towards other, non-human beings, is targeted at showing that moral considerability is a significant component of the decision-making process.

\section{References}

1. Goodpaster, K. On Being Morally Considerable, Journal of Philosophy 75 (6), 1978, pp. 308325.

2. Hale, B. Moral Considerability: Deontological, Not Metaphysical, Ethics \& the Environment 16 (2), 2011, pp. 37-62.

3. Light, A., Holmes Rolston III. Introduction: Ethics and Environmental Ethics, In A. Light, Holmes Rolston III (eds.), Environmental Ethics. An Anthology, Malden (MA): Blackwell Publishing, 2006.

4. Sessions, G. Ecocentrism and the Anthropocentric Detour, In G. Sessions (ed.), Deep Ecology for the twenty-first Century: Readings on the Philosophy and Practice of the New Environmentalism, Boston: Shambhala Publications, 1995.

5. Crutzen, P. J. Geology of Mankind, Nature 415 (6867), 2002.

6. Crutzen, P. J., Stoermer, E. F. The 'Anthropocen,' Global Change Newsletter 41, 2000.

7. Lemmens, P, Blok, V., Zwier, J. Toward a Terrestrial Turn in Philosophy of Technology,

Techné: Research in Philosophy and Technology 21 (2-3), 2017.

8. Blok, V. Earthing Technology: Towards an Eco-centric Concept of Biomimetic Technologies in the Anthropocene, Techné: Research in Philosophy and Technology 21 (2-3), 2017, pp. 127-49.

9. Bennett, J. Vibrant Matter: A Political Ecology of Things, Durham: Duke University Press, 2010. 10. Leopold, A. A Sand County Almanac: And Sketches Here and There, Oxford: Oxford University Press, 1986.

11. Singer, P. Animal Liberation: A New Ethics for Our Treatment of Animals, New York: Avon, 1975.

12. Taylor, P. Respect for Nature, Princeton: Princeton University Press, 1986.

13. Naess, A., Sessions, G. Platform Principles of the Deep Ecology Movement, In A. Drengson, Y. Inoue (eds.), The Deep Ecology Movement. An Introductory Anthology, Berkeley: North Atlantic Books, 1995.

14. Brennan, A. Thinking about Nature. An Investigation of Nature, Value and Ecology, Athens: The University of Georgia Press, 1988.

15. Gorke, M. The Death of Our Planet's Species: A Challenge To Ecology And Ethics, trans. By P. Nevers, Washington, DC: Washington Island Press, 2003.

16. Birch, T. Moral Considerability and Universal Consideration, Environmental Ethics 15 (4), 1993, pp. 313-332.

17. Floridi, L. Information Ethics, its Nature and Scope, In J. van den Hoven, J. Weckert (eds.), Information Technology and Moral Philosophy, Cambridge: Cambridge University Press, 2008. 18. Gunkel, D. The Machine Question Critical Perspectives on AI, Robots, and Ethics, Cambridge (MA): MIT Press, 2012.

19. Hayward, T. Universal Consideration as a Deontological Principle: A Critique of Birch, Environmental Ethics 18 (1), 1996, pp. 55-63.

20. Weston, A. Universal consideration as an originary practice, Environmental Ethics 20 (3), 1998, pp. 279-289. 
21. Singer, P. Practical Ethics, Cambridge: Cambridge University Press, 2011.

22. Bernstein, M. On moral considerability. An essay on who morally matters, Oxford: Oxford University Press, 1998.

23. Gare, A. Ethics, Philosophy and the Environment, Cosmos and History: The Journal of Natural and Social Philosophy 14 (3), 2018. pp. 219-240.

\section{Acknowledgements}

This research was supported by the grant DIALOG 0023/2019 from the Ministry of Science and Higher Education (Poland). 